\title{
Blood and conflict: managing bleeding disorders in Gaza
}

Hala Borno $^{7}$

Preventing and controlling bleeding episodes that occur spontaneously or due to injury is the cornerstone of haemophilia care. The majority of haemophilia A and B cases follow X chromosome-linked inheritance patterns but haemophilia can also arise from single gene mutations leading to a clotting factor deficiency (1-5). While new therapies for haemophilia care have arisen over the past 40 years, today, the usual therapy for haemophilia is factor concentrate, a product routinely developed using recombinant DNA technology $(5,6)$.

Unfortunately, access to this therapy is variable worldwide. An estimated $75 \%$ of affected persons receive inadequate care (7-9). Violent conflict is frequently driven by or creates a scarcity in resources. This cause and effect go handin-hand and hinder the ability of health care systems to provide standards of care for costly chronic conditions, such as haemophilia, in conflict settings.

In Gaza, due to recurrent, multigenerational violent conflict in the setting of an ongoing siege, the Ministry of Health has struggled to meet the basic health care demands of the population (10). Health care providers in Gaza treating high cost and low prevalence diseases including haemophilia face considerable challenges. Despite factor VIII being needed by less than $0.01 \%$ of the population, the Ministry of Health spends more on this medicine than any other drug - and 3 times more than the total spent on insulin $(10,11)$. Even though the Ministry of Health spends $6 \%$ of the total drug expenditure on factor VIII, it can only deliver about $60 \%$ of the amount needed per patient $(2,3,10-12)$. As a result, emergency stores of cryoprecipitate product, which is associated with more adverse events like transmission of bloodborne pathogens and transfusion-related lung injury, are frequently used in order to make up for shortages in the factor VIII supply (4-6,8,13-15).

The effect of conflict on the care of people with haemophilia is complex and not fully measurable at any point in time. People with haemophilia in conflict zones like Gaza face very high risks every day due to the consequences of resource scarcity, ongoing violence and damaged infrastructure. Little research has investigated the added indirect economic and social costs associated with haemophilia care in conflict settings, such as the economic opportunity loss if the condition leads to disability.

In a conflict setting like Gaza, there are several elements that lead to inadequate haemophilia care. The main suppliers of medical equipment and medicines for the Ministry of Health are based in the West Bank and donations made through international organizations are frequently restricted by the siege. Additionally, donations tend to be uncoordinated, leaving the Ministry of Health in Gaza with donations that do not match emergency needs $(10,11)$. A lack of coordination with the Palestinian Authority may also contribute to shortages.

Concrete steps need to be taken to create sustainability in haemophilia care. The Ministry of Health in Gazan needs to strengthen early intervention programmes targeting people with haemophilia in order to avoid the need for long-term musculoskeletal care. More robust donation coordination is needed to ensure that the supply of factor concentrate meets needs, even at times of emergency. Additionally, when necessary, people with haemophilia should be able to travel to tertiary haemophilia care centres in Israel when stores are inadequate in Gaza.

Inadequate haemophilia care has serious consequences including chronic musculoskeletal injury, pain and disability, which further adversely affect the life of haemophilia patients and health care providers. The social and financial costs of inadequate haemophilia care are long-standing, therefore, greater attention to haemophilia care in conflict settings should be a priority.

Funding: None

Competing interests: None declared. 


\section{References}

1. Allen KN, Kachalsky E. Aging with hemophilia: implications for social work practice. Soc Work Health Care. 2010;49(4):32744.

2. Angelis A, Tordrup D, Kanavos P. Socio-economic burden of rare diseases: A systematic review of cost of illness evidence. Health Policy. 2015;119(7):964-79.

3. de Jager T, Pericleous L, Kokot-Kierepa M, Naderi M, Karimi $M$. The burden and management of FXIII deficiency. Haemophilia. 2014;20(6):733-40.

4. Heemstra HE, Zwaan T, Hemels M, Feldman BM, Blanchette V, Kern M, et al. Cost of severe haemophilia in Toronto. Haemophilia. 2005;11(3):254-60.

5. Kar A, Phadnis S, Dharmarajan S, Nakade J. Epidemiology $\&$ social costs of haemophilia in India. Indian J Med Res. 2014;140(1):19-31.

6. Gonzalez-Figueroa M, Canales-Munoz JL, Aguayo-Alcaraz G, Zamora-Vazquez G. Costo directo de la atención medica en niños con hemofilia [Cost of health care in children with haemophilia]. Rev Med Inst Mex Seguro Soc. 2010;48(2):199-204.

7. Skinner MW. WFH: closing the global gap-achieving optimal care. Haemophilia. 2012;18 Suppl 4:1-12.

8. Szucs TD, Offner A, Kroner B, Giangrande P, Berntorp E, Schramm W. Resource utilisation in haemophiliacs treated in Europe: results from the European Study on Socioeconomic Aspects of Haemophilia Care. The European Socioeconomic Study Group. Haemophilia. 1998;4(4):498-501.
9. World Federation of Hemophila. Annual Global Survey Data. 2013 (http://wwwl.wfh.org/GlobalSurvey/Public_AGS/AGS_ Bleeding_Disorders_Map.aspx, accessed 28 May 2017).

10. World Health Organization Regional Office for the Eastern Mediterranean. WHO releases short video on impact of drug shortages on haemophilia patients in the Gaza Strip. Press release 2014 (http://www.emro.who.int/palestine-pressreleases/2014/who-launches-short-video-impact-of-drugshortages-on-hemophilia-patients-in-gaza.html, accessed 28 May 2017).

11. World Health Organization. Essential Medicines and Health Products Information Portal. Drug situation analysis for the West Bank and Gaza Strip (http://apps.who.int/medicinedocs/en/d/Js6155e/7.4.html, accessed 28 May 2017)

12. Ford ME, Siminoff LA, Pickelsimer E, Mainous AG, Smith DW, Diaz VA, et al. Unequal burden of disease, unequal participation in clinical trials: solutions from African American and Latino community members. Health Soc Work. 2013;38(1):29-38.

13. Kodra Y, Cavazza M, Schieppati A, De Santis M, Armeni P, Arcieri $R$, et al. The social burden and quality of life of patients with haemophilia in Italy. Blood Transfus. 2014;12 Suppl 3:s567-75.

14. Nascimento B, Goodnough LT, Levy JH. Cryoprecipitate therapy. Br J Anaesth. 2014;113(6):922-34.

15. Shapiro AD, Donfield SM, Lynn HS, Cool VA, Stehbens JA, Hunsberger SL, et al. Defining the impact of hemophilia: the Academic Achievement in Children with Hemophilia Study. Pediatrics. 2001;108(6):E105. 